rev.relac.int.estrateg.segur.8(2):95-116,2013

\title{
TERRITORIO ANTÁRTICO CHILENO: LA REACCIÓN DE CHILE ANTE LOS INTERESES ANTÁRTICOS GLOBALES*
}

\author{
Fernando Villamizar ${ }^{* *}$ \\ Patricio Ibarra ${ }^{* * *}$ \\ Cristián Guerrero ${ }^{* * * *}$
}

\section{RESUMEN}

El objeto de este artículo es presentar una visión respecto de cómo históricamente Chile se ha preocupado por la Antártida, debido a un escenario internacional en el cual se presenta un creciente interés por el ejercicio de la influencia y el control del continente blanco. Mientras que varios países del mundo se empezaron a preocupar por la Antártida, el Chile republicano e independiente en un principio no manifestó un interés sobre los confines polares, pero al percatarse de las acciones realizadas por diversas potencias y los recursos que estas materializan a fin de obtener el control territorial

* Este artículo es una reflexión fruto de la Tercera Cátedra Bernardo O’Higgins Sobre Estudios Antárticos celebrada en Santiago de Chile entre abril y julio de 2013.

** Director del Observatorio Regional de Paz y Seguridad (ORPAS) de la Universidad Bernardo O’Higgins. Doctor en Ciencia Política y Sociología. Comentarios a: fvillamizar@ubo.cl

*** Investigador del Centro de Estudios Históricos de la Universidad Bernardo O'Higgins. Doctor (c) en Historia. Comentarios a: patricio.ibarra@ubo.cl.

**** Investigador del Centro de Estudios Históricos de la Universidad Bernardo O'Higgins. Doctor en Historia. Comentarios a: cristian.guerrero@ubo.cl. 
antártico, el Estado chileno reaccionó y realizó una reclamación territorial. El artículo emplea una cronología fraccionada en seis etapas claramente diferenciables por las actividades y por la visión que se tenía del continente blanco, y por medio de ésta se contrastan las actividades realizadas en la Antártida por las potencias y las realizadas por Chile.

Palabras clave: Antártida, Territorio Antártico Chileno, Intereses Antárticos, Concesiones Balleneras, Exploración Antártica, Tratado Antártico

\title{
CHILEAN ANTARCTIC TERRITORY: THE REACTION OF CHILE TO THE ANTARCTIC GLOBAL INTERESTS
}

\begin{abstract}
The purpose of this article is to present an overview on how Chile has historically been concerned with the Antarctic, due to an international scenario which shows a growing interest to exert influence and control of the white continent. While several countries began to worry about the Antarctic, the republican and independent Chile initially expressed no interest on the polar region, but when Chile perceived the actions taken by various powers and the resources they used in order to attain Antarctic territorial control, then the Chilean government reacted and made a territorial claim. This article uses a timeline divided into six stages clearly distinguished by the activities and the vision that existed on the white continent, and through it, a contrast is made of the activities conducted in the Antarctica by the powers and by Chile.
\end{abstract}

Keywords: Antarctica, Chilean Antarctic Territory, Antarctic Interests, Whaling Concessions, Antarctic Explorations, Antarctic Treaty

\section{TERRITÓRIO ANTÁRTICO CHILENO: A REAÇÃO DO CHILE PERANTE O INTERESSE ANTÁRTICO GLOBAL}

\section{RESUMO}

O objetivo deste artigo é apresentar uma visão geral sobre como historicamente o Chile tem se preocupado pela Antártica, devido a um cenário internacional, no qual existe um interesse crescente por exercer influência e controle do continente branco. Enquanto vários países do mundo começaram a se preocupar com a Antártica, o Chile republicano e independente inicialmente não manifestou nenhum interesse pelos confins polares, mas ao perceber as ações tomadas por várias potências e os recursos que elas dispuseram a fim de obter um controle do território antártico, o governo chileno reagiu e fez uma reivindicação territorial. O artigo utiliza um cronograma dividido em seis etapas claramente distinguidas pelas atividades e pela visão 
que se tinha do continente branco, e por meio dela se contrastaram as atividades desenvolvidas na Antártica pelas potências com as realizadas pelo Chile.

Palavras-chave: Antártica, Território Antártico Chileno, Interesses Antárticos, Concessões Baleeira, Exploração Antártica, Tratado Antártico

\section{INTRODUCCIÓN}

¿Cómo ha sido el desarrollo de la incorporación del territorio antártico reclamado por Chile? ¿Cuál ha sido el contexto internacional en que se ha desarrollado esa incorporación territorial? Este artículo busca responder esas dos preguntas bajo la hipótesis de que Chile primero buscó consolidar los territorios más próximos, y debido a la presión internacional que se proyectaba progresivamente en la Antártida ${ }^{1}$, implementó una política reactiva dirigida a reclamar y delimitar el llamado "Territorio Antártico Chileno".

Para efectos de probar la hipótesis planteada, se describirá la evolución histórica de las relaciones antárticas, utilizando la propuesta cronológica expuesta por Robert K. Headland (1989). En ese análisis de las relaciones antárticas, se podrá apreciar la influencia de las potencias imperiales europeas y de Estados Unidos hasta la consolidación del Tratado Antártico, y paralelamente cómo actuaba Chile para efectos de consolidar dentro de su territorio aquellos espacios y porciones marítimas comprendidas entre el meridiano $53^{\circ} \mathrm{O}$ y el meridiano $90^{\circ} \mathrm{O}$.

\section{LA ANTÁRTIDA: DEL DESCUBRIMIENTO A LA DIPLOMACIA, EL CAMINO DESDE LA TERRA AUSTRALIS HASTA EL TRATADO ANTÁRTICO}

Las aproximaciones hacia la Antártida han evolucionado con el transcurso del tiempo. Acogiendo la clasificación de Robert K. Headland (1989), dicha evolución se puede fraccionar en seis etapas claramente diferenciables por las actividades y por la visión que se tenía del continente blanco.

\subsection{TERRA AUSTRALIS}

La primera etapa se conoce como Terra Australis y se remonta desde tiempos inmemoriales hasta 1780. En esta etapa tan extensa encontramos visiones que van desde lo intuitivo hasta le

1. Respecto del empleo de los términos "Antártida" y "Antártica", cuando se alude al primero es porque es el sustantivo y el segundo se emplea cuando es adjetivo. 
empírico. Dentro de las primeras se destaca la de Ptolomeo, quien en su obra Geografía consideró a la Antártida como una necesidad física para el equilibrio de la Tierra, en la medida en que la presencia de ese continente contrarrestaría el peso del polo norte, generándose así el equilibrio del planeta (Vilanovano, 1932).

En el campo de lo empírico hay una larga lista de navegantes que bajo condiciones extremas hicieron progresivos descubrimientos de la Antártida. Empecemos por destacar lo realizado por Sir Francis Drake, quien en 1578, después de atravesar el Estrecho de Magallanes, fue arrastrado por las tempestades hacia el Sur y pudo comprobar que el Atlántico y el Pacífico se unían más allá de la Tierra del Fuego, desechando así todo pretendido enlace con otros continentes; también se destaca en el siglo XVI el descubrimiento hecho por Jacobo Mahú, que zarpó el 27 de junio de 1598 y llegó a lo que hoy se conoce como Shetland austral (Pinochet de la Barra, 1944:11-12).

En 1603, el barco holandés Blijde Bootschap, comandado por Dirck Gherritz, navegaba al sur del Cabo de Hornos cuando una tormenta lo arrastró hasta los 64을 de Latitud Sur, y en virtud de esto pudo divisar unas montañas cubiertas de nieve que le recordaron a Noruega, pero que en realidad eran la Antártida (Campbell, 2002:153). Tras varios intentos de poca relevancia, o de escasa recordación, en abril de 1675 se produce un acontecimiento relativamente importante en el territorio antártico: el descubrimiento de la isla Georgia del Sur, que si bien ha sido atribuido a Anthony de la Roché, se presume que fue vista por Américo Vespucio (Ferrer, 2003:3).

Durante el siglo XVIII hubo varias expediciones que intencionada o fortuitamente tuvieron contacto con el continente blanco. Nombres como los de Lozier Bouvet o Marión du Frezne, adquieren relevancia por sus aportes al conocimiento de la geografía antártica, pero tal vez las contribuciones más notables en ese sentido fueron las de Yves - Joseph Marie de Kerguelen de Trémarec y James Cook. Kerguelen descubrió un archipiélago situado en el Océano Índico y que lleva su apellido, islas Kerguelen (Autissier, 2006), y Cook realizó varias travesías por las regiones antárticas entre 1772 y 1776 . A él corresponde el descubrimiento de las islas Sándwich, el redescubrimiento de la isla Georgia y la hazaña extraordinaria de haber atravesado por primera vez el círculo polar en su pequeño barco llamado Resolution (Preston, 1999:10). Sin embargo, Cook no pudo encontrar el pretendido continente polar.

\subsection{EL REINO DE CHILE Y LOS CONFINES DE LA TERRA AUSTRALIS}

Los derechos de soberanía que la República de Chile reclama sobre parte del continente antártico desde 1940, y aquellos en que basó su posición en la fijación de sus límites australes, derivan de la actualización, por medio de la aplicación del Uti Possidetis de 1810, de los que la corona española tenía sobre los mismos territorios a partir de 1493 cuando por medio de la bula Inter Caetera se trazó un límite entre esa monarquía y la de Portugal, que fue posteriormente modificado por acuerdo entre esas potencias en 1494. 
De acuerdo con esos textos, España empezó a conceder licencias para la conquista y poblamiento de territorios que incluían tanto el estrecho de Magallanes como la Antártida, cuya existencia aún era supuesta, presumiéndose incluso una continuidad territorial desde la ribera sur del estrecho hacia el polo. Así, en 1534 se concedió autorización a Simón de Alcazava para ocupar las tierras situadas entre el paralelo $36^{\circ}$ de latitud sur y el paso interoceánico, pero la empresa fracasó, al igual que la que dos años después encabezó Francisco de Camargo. En 1539 se dio un nuevo paso por la capitulación de Pedro Sancho de Hoz con la corona la conquista de las tierras situadas al sur del estrecho, prometiéndose que "hecho el dicho descubrimiento de la otra parte del dicho estrecho, o de alguna isla que no sea en paraje ajeno, os haremos la merced a vuestros servicios; i entre tanto que nos somos informados de lo que así descubriéredes, seáis nuestro gobernador de ello" (Amunátegui, 1879:129). El derecho a emprender esta conquista fue cedido, no voluntariamente, aunque el documento pertinente así lo afirme, por Sancho de Hoz a Pedro de Valdivia en agosto de 1540.

Valdivia había iniciado la conquista de Chile en calidad de teniente de Gobernador de Francisco Pizarro, pero al poco tiempo fue nombrado gobernador por el cabildo de Santiago (1541), título provisorio hasta la confirmación real, y que solo fue sancionado en 1548, pero para la Nueva Extremadura, es decir, el área jurisdiccional que se extendía desde Copiapó hasta los 410 de latitud sur, con lo que la cesión de Sancho de Hoz no fue reconocida por la corona. Algunos autores concluyen de esto que Valdivia poseía en el fondo dos gobernaciones, lo que estimamos incorrecto ${ }^{2}$. Si bien Valdivia envió a la Corte a Jerónimo de Alderete a conseguir la extensión de la nueva Extremadura hasta el estrecho, lo que se logró en 1554, el mismo enviado logró suscribir su propia capitulación en la que se le concedió la gobernación de las tierras al sur del estrecho de Magallanes y al poco tiempo se le nombró gobernador de Chile al conocerse en la Península la noticia de la muerte de su mandante. Este punto resulta de importancia pues se unen en un solo territorio dos secciones distintas.

Alderete no llegó a ejercer el gobierno y al ser nombrado su sucesor, García Hurtado de Mendoza, se le asignó un territorio que comprendía las tierras situadas hasta "el estrecho de Magallanes inclusive", lo que indica la inclusión de las dos riberas del paso. Años más tarde (1558), al nombrarse a Francisco de Villagra, el rey expresó en el documento correspondiente que tenía a bien ampliar la gobernación de Chile 170 leguas "hasta el estrecho de Magallanes", encargándosele al mismo gobernador recién nombrado, por otra disposición, que enviara una relación de las tierras "que hay de la otra parte del Estrecho" y que tomara posesión de ellas.

La fijación de la jurisdicción de las instituciones posteriormente creadas, también evidencia la inclusión del estrecho de Magallanes. Así ocurrió, por ejemplo, en 1609 al establecerse la Real

2. La cesión de Sancho de Hoz a Valdivia no podía obligar a la Corona, porque esta había capitulado con el primero. 
Audiencia en Santiago, a la que se fijó una circunscripción que incluía todo el territorio del reino, incluyéndose lo que a futuro se poblase a ambos lados del paso interoceánico.

En 1776, al crearse el virreinato del Río de la Plata, se segregó de Chile la provincia de Cuyo, estableciéndose un nuevo límite entre ambas unidades administrativas en la ribera del río Diamante, desde donde se prolongaba hacia el este hasta el punto en que el río Quinto atravesaba el camino entre Buenos Aires y Mendoza. Según el mapa confeccionado oficialmente por Juan de la Cruz Cano y Olmedilla un año antes, Chile poseía las tierras situadas desde la península de Mejillones hacia el sur, siendo su frontera oriental la cordillera de los Andes. Esta era, entonces, la conformación del territorio hacia 1810 cuando se inició el proceso de independencia.

\subsection{EL PERÍODO DE CAZA DE FOCAS}

Este período se extiende desde 1780 hasta 1892. La importancia de la caza de focas se explica, en un principio, por que eran una buena fuente alimenticia para los navegantes, y posteriormente, cuando llega a la máxima explotación, por el valor comercial de su aceite y de su cuero, que era intercambiado en China a un alto precio (Braun, 1974:13). De hecho, la actividad de caza de focas fue tan intensiva que varias especies casi llegaron a la extinción (Rogers, et al., 2012:495). Solo entre 1801 y 1802 se cazaron 112.000 en South Georgia (Headland, 1992:34).

Pero la importancia de este período, de cara al conocimiento de la Antártida, radica en que ante la escasez progresiva de focas, los cazadores empezaron a expandir su búsqueda en las zonas exteriores antárticas, y con ello se empezó una progresiva exploración del continente blanco, bajo tres diferentes aproximaciones:

(i) Exploraciones con el objeto exclusivo de cazar focas y sin ningún interés científico, de las cuales hay poco respaldo documental; sin embargo, existen testimonios, como el de Bellingshausen (1945), quien en su travesía da cuenta de una desbordante actividad de caza de focas.

(ii) Exploraciones que buscan cazar focas y también hacer descubrimientos, como ocurrió con la expedición patrocinada por los armadores londinenses Enderby, quienes confiaron al capitán John Biscoe una expedición con el objetivo de cazar focas y hacer nuevos descubrimientos, entre los cuales se destacan la isla de Adelaida, la Tierra de Graham y las islas Biscoe (Cumpston y Biscoe, 1963).

(iii) Exploraciones con un objetivo científico y sin el ánimo de cazas focas con fines comerciales, entre las cuales las más relevantes fueron las de James Weddel en 1823, la del capitán francés Dumont d'Urville en 1838 y la de James Ross, quien en los buques Erebus y Terror se dispuso, entre 1839 y 1843, a hacer una exploración que dejó sendas huellas en el 
conocimiento geográfico de la Antártida, al punto tal que varios accidentes geográficos tienen hoy en día el nombre puesto por Ross, como dos volcanes a los cuales los llamó como sus barcos, Erebus y Terror, y el llamado Mar de Ross (Ross, 1994).

\subsection{EL PERÍODO DE CAZA DE FOCAS Y EL CHILE DECIMONÓNICO: LA CONSOLIDACIÓN DEL TERRITORIO CONTINENTAL E INSULAR}

En Chile, primero con la declaración de Independencia en febrero de 1818 y luego con el triunfo de las armas del 5 de abril en los campos de Maipo, terminó la revolución por la emancipación, y se dio inicio al proceso de formación de las instituciones republicanas, que tomaría al menos cuatro décadas, alternando cambios y continuidades, adelantos y retrocesos, éxitos y fracasos.

La década de 1820 fue de experimentación. En los textos constitucionales de 1822, 1823 y 1828, a los que se debe agregar el fallido experimento federal de 1826, se propusieron diversas fórmulas de administrar el Estado y las tensiones de la vida en sociedad, disputa que si bien se materializó en controversias políticas, fue finalmente zanjada por las armas para luego institucionalizarse a través de un régimen conservador que se prolongó por treinta años bajo el amparo de la Constitución de 1833.

La discusión en torno a la necesidad de instituciones sólidas y duraderas para la República también significó establecer e intentar ejercer un control efectivo del territorio. Aquello fue un proceso largo y con sobresaltos. En la Constitución de 1822, dictada durante el gobierno de Bernardo O'Higgins meses antes de su abdicación en enero de 1823, se estableció que el espacio chileno reconocía por "límites naturales al Sur, el Cabo de Hornos; al Norte, el despoblado de Atacama; al Oriente, los Andes: al Occidente, el Mar pacífico: le pertenecen las Islas del Archipiélago de Chiloé, las de la Mocha, las de Juan Fernández, la de Santa María, y demás adyacentes" (Constitución Política 1822). Esos serían los límites a partir de los cuales el Estado chileno inició su expansión territorial. De allí en adelante, durante el siglo XIX, en las ya mencionadas cartas de 1823, 1828 y 1833, la demarcación citada se mantuvo inalterada. Así, desde los inicios de la República y durante todo el siglo XIX, se reconoció como límite sur chileno el Cabo de Hornos, sin considerar al territorio antártico como propio.

¿Era posible que la joven nación pudiera hacer efectivos los derechos que reclamaba en tan vasto territorio? Difícilmente podría hacerlo. Las urgencias generadas por un erario fiscal esquilmado por la larga guerra de la Independencia, las necesidades generadas por la organización de la Expedición Libertadora del Perú y también por la necesidad de echar andar la maquinaria estatal necesaria, entre otras razones, impedían un efectivo apropiamiento del espacio señalado como propio. En efecto, el bastión leal a la monarquía española instalado en Chiloé, que fue incorporado de facto al territorio chileno por el plan de defensa del reino de Chile de 1810 de modo que pasó a depender de Lima desde 1768 (Barros Arana, 1905:13), remanente de los 
años de la revolución emancipadora, se extendería hasta 1826. La operación militar que permitió su integración se debió al interés mostrado por el Perú para apropiarse de la zona, aduciendo que había sido jurisdicción del Virrey y que por ende le correspondía. Finalmente, el tratado de Tantauco, de enero 15 de 1826 (Barros Arana, 1897: 631), integró en forma definitiva a Chiloé a Chile. Con todo, fue el primer paso de un largo camino hacia la apropiación del espacio declarado como propio.

La década de 1830 tuvo sus propios afanes. El primero fue fortalecer las instituciones para forjar la nación y la República, materializado en la Constitución de 1833. En ese contexto, un conflicto externo fortalecería el medio interno: la guerra contra la confederación peruano-boliviana. La derrota propinada por el Ejército Restaurador a los intentos del mariscal Andrés de Santa Cruz por crear un referente continental con la unión política y territorial de Perú y Bolivia, tonificó el carácter, la identidad nacional y la posición relativa de Chile en el concierto latinoamericano, apuntalándolo como un país respetable y vigoroso ante los ojos de sus vecinos y ante sí mismo (Cid, 2011). En definitiva, las victorias conseguidas por el general Manuel Bulnes y el roto en Yungay, permitieron el fortalecimiento del Estado-nación, dando el impulso político y económico imprescindible para consolidar las fronteras internas, que décadas más tarde permitirían también la expansión hacia nuevos territorios a expensas de sus vecinos del norte.

El paso siguiente, y el más significativo, desde la perspectiva de la incorporación efectiva al dominio de la zona austral como parte del Estado chileno, fue la toma de posesión del Estrecho de Magallanes. Una expedición financiada por el gobierno de Manuel Bulnes, organizada por el intendente de Chiloé, Domingo Espiñeira, comandada por Juan Williams Rebolledo, con la presencia del naturalista prusiano Bernardo Eunom Philippi y acompañados del piloto estadounidense George Mabon, fue enviada a bordo de la Ancud a los agitados mares del sur para hacer flamear la estrella solitaria y el tricolor en el extremo austral de América.

Así, el 21 de septiembre de 1843 la excursión tomó posesión del Estrecho de Magallanes, fondeando en Punta Santa Ana. Este acto representó un esfuerzo concreto por materializar lo expresado en las constituciones chilenas decimonónicas respecto de la frontera chilena austral, ante las ambiciones de potencias extranjeras -como Francia-, quienes también depositaron sus intereses en una zona que posee la llave maestra del tránsito entre los océanos Pacífico y Atlántico, clave en esa época para el control del comercio entre Europa y la costa occidental del Nuevo Mundo. Días más tarde, el 30 de octubre, a eso de las 6 de la tarde, tras los ritos cívicos y militares correspondientes, Williams enarboló el tricolor en la ceremonia que marcó la fundación del Fuerte Bulnes. Con este acto el Estado chileno asentó su presencia y soberanía en el Estrecho de Magallanes. Desde ese lugar se expandió la presencia del Estado chileno en los confines australes americanos (Martinic, 1977:133-134).

Tan importante como la toma de posesión del Estrecho de Magallanes, fue la fundación de Punta Arenas. A poco andar, las duras condiciones de vida en los parajes del Fuerte Bulnes 
hicieron mella en los colonos que allí habitaban, haciéndolos buscar un mejor lugar donde establecerse. Abriéndose paso entre frondosos bosques, lograron acceder a la pampa de Punta Arena (Sandy Point, según las cartas de navegación de los marinos ingleses) donde podían subsistir sin mayores sobresaltos los pobladores y el ganado que servía para su sustento, pues el clima presentaba mejores condiciones y su suelo era más productivo que donde se encontraban. En ese lugar, a partir de febrero de 1849, se construiría la nueva ciudad de Punta Arenas, estableciendo allí la colonia desde donde se haría efectiva la presencia chilena en el Estrecho de Magallanes y, mediante su consolidación como ciudad durante las décadas siguientes, se proyectarían los intereses chilenos sobre la Antártida. (Martinic, 1977).

En paralelo, asociado al interés del Estado chileno por apropiarse efectivamente de su territorio, la administración de Manuel Bulnes promulgó en 1845 una ley de colonización, con la cual se inició el proceso de inmigración de colonos europeos a la zona de Valdivia y Llanquihue. En el periodo, arribaron al sur de Chile entre 30.000 a 40.000 alemanes. En definitiva, la política de incentivo a la llegada de inmigrantes de origen germano principalmente, permitió que el Estado avanzara hacia la incorporación efectiva de la zona a la soberanía chilena.

En la práctica, en la década de 1840 el Estado chileno se consagró a la consolidación de sus fronteras norte y sur. Junto al afianzamiento del límite sur, el gobierno de Bulnes declaró como propiedad chilena los importantes depósitos de guano descubiertos al sur de la bahía de Mejillones, concediéndoles la licencia de explotación a los empresarios chilenos que descubrieron las reservas de ese fertilizante. Como era de esperar, la medida disgustó a las autoridades bolivianas. Ese sería el comienzo de los roces de Chile con sus vecinos del norte por el caliche.

En la década de 1850, la mirada y los afanes se volcarían allende los Andes. En octubre de 1855 se firmó un tratado con Argentina. Buenos Aires y Santiago suscribieron el "Tratado de paz, amistad, comercio y navegación" que estableció un sistema de paridad de derechos y deberes para los ciudadanos que desarrollasen actividades económicas en ambos territorios, la protección de sus intereses y propiedades, y la colocación de la estructura de administración y comunicación de los respectivos países al servicio del comercio y la industria. Sin embargo, también contempló la delimitación del territorio, señalando en su artículo 39 que "Ambas partes contratantes reconocen como límites de sus respectivos territorios, los que poseían como tales al tiempo de separarse de la dominación española el año de 1810, y convienen en aplazar las cuestiones que han podido o pueden suscitarse sobre esta materia para discutirlas después pacífica y amigablemente, sin recurrir jamás a medidas violentas, y en caso de no arribar a un completo arreglo, someter la decisión al arbitraje de una nación amiga" (Colección..., 1857:21) Se señalaba, entonces, la vigencia del Uti possidetis de 1810, y se aplazaba para el futuro la discusión por las cuestiones limítrofes existentes o por surgir (Eyzaguirre, 1989). Con todo, en ese momento ya se vislumbraba la disputa que vendría por la Patagonia, a partir de las reclamaciones argentinas por las tierras australes y las refutaciones chilenas cuyo derrotero es posible seguir en los Títulos de la 
República de Chile a la soberanía de la extremidad austral del continente americano, escrita por Miguel Luis Amunátegui (1855).

La guerra hispano-sudamericana, librada en las costas chilenas y peruanas entre 1865 y 1866 , volcó a estos países a un conflicto con el otrora dominador colonial, ante la supuesta ofensa a la soberanía de las jóvenes naciones sudamericanas. La exacerbación de la fraternidad americana trajo como consecuencia la necesidad de concretar una alianza chileno-argentina, temiéndose el resurgimiento de los afanes colonialistas españoles a partir del conflicto en curso. Para ello, La Moneda envió a Buenos Aires a José Victorino Lastarria, quien fracasó en su cometido. No pudo concretar asociación alguna ni acuerdo limítrofe, pues el acuerdo logrado fue rechazado por las propias autoridades chilenas al considerarlo desfavorable. El ministro del Interior y Relaciones Exteriores de la época, Álvaro Covarrubias, señaló a Lastarria que "no podríamos renunciar, en ningún caso, al dominio de todo el Estrecho de Magallanes y de las tierras adyacentes" (Eyzaguirre, 1989). De ese modo terminó la discusión del caso. Sin embargo, el contencioso tendría un nuevo capítulo en la década siguiente.

Por esa misma época el Estado chileno volcó su mirada hacia el norte. En agosto de 1866, (Colección, 1875:53) firmó un Tratado limítrofe con Bolivia fijando el territorio de su dominio en el Despoblado de Atacama, estableciendo la frontera en el paralelo 24ㅇ. Empero, los problemas producidos por la aplicación del acuerdo, obligó a Santiago y La Paz a negociar nuevamente. Así, el 6 de agosto de 1874 se acordó que el límite se mantuviera en el paralelo 24ㅇy y Bolivia se comprometió a no cobrar, por 25 años, otros impuestos fuera de los ya existentes a personas, empresas y capitales chilenos (Colección, 1875:148) Sin embargo, la violación boliviana de esta cláusula, materializada en el cobro de 10 centavos por quintal de salitre, fue el casus belli de la Guerra del Pacífico (Guerra del Salitre) en 1879, que se extendió hasta 1884, involucrando al Perú que estaba unido con la nación altiplánica a través de un acuerdo secreto desde 1873 (Barros Van Buren, 1970:305- 307). Para Chile, la victoria en ese conflicto significó la incorporación de Tarapacá y Arica, mediante los tratados de 1883 y 1929 (Barros Van Buren, 1970: 769-772). Así, con este último, Chile estableció lo que hoy reconoce como su frontera norte.

Por otra parte, a fines de 1878 y comienzos de 1879 se esperaba que el conflicto estallara en el sur. El paréntesis entre el fracaso de la misión de Lastarria y la firma del tratado de límites con Argentina de 1881 (Barros Van Buren, 1970:392-393), fue largo y tortuoso. Los problemas por la posesión de la Patagonia y el dominio del Estrecho de Magallanes escalaron a tal punto que los gobiernos de ambos países consideraron la posibilidad de una confrontación militar. El fracaso del Tratado Fierro-Sarratea, que establecía la sesión por parte de Chile de sus derechos sobre la Patagonia y declaraba la neutralidad del Estrecho de Magallanes, llevó la situación al límite.

Una vez que las tropas chilenas habían ingresado a Lima y se iniciaba la penosa campaña en la sierra peruana impulsada por caudillos que se negaban a firmar la paz, Chile suscribió el Tratado de Límites de 1881 con Argentina, protocolizado el 23 de julio poco después de terminar el 
periodo del presidente Aníbal Pinto. En lo esencial, dispuso que la frontera de norte a sur hasta el paralelo $52^{\circ}$, fuera la línea de las "cumbres más elevadas" de la cordillera de los Andes que dividieran las aguas. La Tierra del Fuego fue fraccionada por una línea que se iniciaba en el norte desde el Cabo de Espíritu Santo hasta tocar en el canal Beagle, quedando para Chile la parte occidental y para Argentina la zona oriental. Respecto de las islas, se dispuso que Chile ejercería su soberanía en "todas las islas al sur del Cabo de Hornos y las que haya al occidente de la Tierra del Fuego". Para el Plata, quedarían la isla de los Estados y todos los islotes próximos, además de las islas en el Atlántico cercanas a la Tierra del Fuego. Sin embargo, este acuerdo no fue suficiente para terminar con los problemas.

En lo sustancial, pese a la cesión de la Patagonia, Chile logró resguardar sus intereses en el Estrecho de Magallanes. Ambas orillas del paso transoceánico son parte de su territorio y las aguas quedarían neutrales. Más aún, quedaron para Chile las islas Nueva, Picton y Lenox, cuya posesión sería fundamental para la proyección hacia la Antártida. La posesión de esas islas estarían en el centro de la disputa que estuvo a punto de provocar la guerra entre Chile y Argentina a fines de 1978.

El contexto de la discusión del tratado de 1881 no fue fácil para Chile. Como ya se mencionó, desde 1879 los chilenos libraban una guerra contra sus vecinos del norte. El estallido del conflicto supuso para las autoridades chilenas que Argentina pudiera hacer causa común con el Perú y Bolivia y a partir de ello La Moneda optó por negociar con Buenos Aires antes de abrir un nuevo frente de batalla. Ya en diciembre de 1879 Domingo Santa María, quien asumiría la primera magistratura de Chile en 1881, señaló: "Hoy no podemos ni debemos discutir con la República Argentina." (Santa María, 1918:73).

¿Se optó por el norte salitrero debido a que se considera más productivo que la Patagonia? ¿Las salitreras eran más atractivas para los chilenos que los agrestes parajes patagónicos? La respuesta a esas interrogantes parece ser afirmativa. La extensa pampa al oriente de los Andes no ofrecía el estímulo suficiente para que el gobierno chileno se interesara activamente en ella. A ello se debe agregar que el gobierno chileno no deseaba involucrarse en una nueva guerra, quizás más sangrienta y penosa que la librada con el Perú y Bolivia.

Complementariamente, Chile extendió sus dominios hacia el Océano Pacífico. En 1888 se anexó Rapa Nui (Isla de Pascua), territorio por entonces habitado por aborígenes y misioneros europeos cuya principal actividad era la ganadería ovina. A fines de la década de 1860, el Estado chileno intentó tomar posesión de la isla enviando un buque para tal efecto, empero la empresa fracasó pues un periódico de Valparaíso informó, erradamente, que se trataba de un territorio en ese momento bajo la tuición de Francia. Con todo, el interés chileno por la Isla persistió. Terminada la Guerra del Pacífico, renació la atención de la opinión pública chilena por la isla, y en 1887 La Moneda decidió comprar los terrenos a John Norman Brander, quien se había adjudicado por remate público las propiedades de la sucesión Brander - Bornier, antiguo propietario del lugar. 
En septiembre de ese año, la autoridad eclesiástica de Tahití cedió su jurisdicción eclesiástica sobre la isla al arzobispado de Valparaíso. En ese contexto, el 9 de septiembre de 1888 arribó a Rapa Nui la Angamos, a las órdenes del capitán Policarpo Toro para tomar posesión formal de ella. En la ocasión se firmó "un acta de cesión por parte del rey Atamu Tekena y seis de los jefes principales, (otras fuentes señalan "doce nativos principales") oficiando de testigos los señores Salmon, Brander y dos de sus empleados". Empero, el paso del territorio insular a la jurisdicción chilena solo ocurrió el año 1890 (Cristino - Fuentes, 2011).

\subsection{EXPLORACIÓN CONTINENTAL ANTÁRTICA}

Esta etapa comprende los años que van desde 1893 hasta 1918, y se enmarca en la dinámica del imperialismo europeo, cuya consecuencia fue que un quinto de la superficie de la tierra y una décima parte de sus habitantes quedaran comprometidos en los dominios en expansión de los conquistadores en una generación. Joseph Chamberlain resumió este desenlace en una frase: "El día de las naciones pequeñas ha pasado; ha llegado el día de los imperios." (Brunn, 1993:171).

Fue tal el auge imperial que hacia 1890 los territorios "vacantes" empezaron a escasear en el mundo (Miralles, 1996:77), y es por esto que la Antártida, continente inhóspito y desconocido, entró en los planes de conquista por parte de diversos Estados. Este ánimo imperial se concretó en el VII Congreso Internacional de Geografía, realizado en Berlín en 1899, que es el evento base para la realización de la Campaña Antártica Internacional llevada a cabo entre 1901 y 1905, y que contó con cinco expediciones, una británica, una alemana, una sueca, una escocesa y finalmente una francesa (Braun, 1974:41). Un hecho relevante de estas excursiones fue la construcción de la primera base meteorológica permanente en 1903, en las Islas South Orkney (Headland, 1989:27).

Por su parte, la Campaña Antártica Internacional dio lugar a lo que autores como Preston (1999) o Huntford (2010) denominan carrera por el polo y otros la era heroica (Howkins, 2009). Quien comienza esta fase fue Sir Ernest Schakleton ${ }^{3}$, quien inició una excursión en 1908-09 a bordo del Nimrod, y el 9 de enero de 1909 llegó a donde ningún humano había llegado hasta entonces: $88^{\circ} 23^{\prime}$. Pese a este gran record, las difíciles condiciones del territorio antártico y la falta de provisiones le impidieron lograr la meta pretendida, que era llegar al Polo Sur. Schackleton estuvo a 170 kilómetros aproximadamente de concretar su objetivo (Ainsberg, 2010:xii).

Posteriormente, y sin tener mutuo conocimiento, en 1911 partieron las dos excursiones que le dieron nombre a la denominada carrera por el polo. El 20 de octubre de 1911, el noruego Roald

3. Conocido por su liderazgo en la fallida excursión del Endurance (1914), por el cual pudo hacer sobrevivir a todo su personal por meses hasta que fueron rescatados por el escampavía chileno Yelcho. 
Amundsen inició la excursión que pretendía llegar al Polo Sur. Unos días después, el primero de noviembre, Robert Falcon Scott inició también su propia carrera, pero antes de su fatídica muerte tuvo una gran decepción porque el 18 de febrero de 1912, cuando llegó al punto matemático en donde se ubica el Polo Sur, se encontró con una flameante bandera noruega, que había sido colocada un mes y un día antes por Amundsen (Preston, 1999).

Con estos acontecimientos se consolidó esta etapa de exploración continental, que se vio frustrada en buena medida por la Primera Guerra Mundial, pues las potencias que podían asumir mayores desafíos en la Antártida debieron movilizar sus recursos para ese evento bélico.

\subsection{CHILE Y LA ETAPA DE EXPLORACIÓN CONTINENTAL: LAS PRIMERAS RECLAMACIONES}

Hacia fines del 1800, mientras los europeos iniciaban una nueva etapa de acercamiento hacia la Antártida, el Estado chileno también miraba hacia el sur, pero por motivos diferentes. El fantasma de la guerra nuevamente rondó entre los pueblos del extremo sur americano. Las diferencias en la interpretación del principio de la divisoria de aguas, sumado a la disputa por la Puna de Atacama elevaron la temperatura entre Chile y Argentina, y se especuló otra vez con el estallido de un conflicto armado. Afortunadamente, una comisión arbitral en marzo de 1899 zanjó el tema y Chile obtuvo alrededor de un tercio del terreno en controversia.

Complementariamente, en 1902 se firmaron en Santiago dos acuerdos conocidos como los "Pactos de Mayo" (Barros Van Buren, 1970: 608-612). El primero tenía por objeto nombrar al Rey de Inglaterra como árbitro permanente para solucionar todas las dificultades que pudiesen surgir en el futuro, mientras que con el segundo, se pretendía terminar con la carrera armamentista desatada entre ambos países, estableciéndose una limitación de posesión de armamentos y la equivalencia de sus respectivas flotas navales.

En un proceso con matices propios, pero complementario al escenario internacional, Chile desplegó plenamente sus intereses sobre la Antártida. Los años que median entre 1906, cuando el gobierno chileno formalizó la primera concesión de explotación de recursos naturales al sur de las islas de Diego Ramírez, y 1959, cuando se suscribió el Tratado Antártico, están marcados por la activa defensa que el Estado chileno hizo de sus derechos ante las reclamaciones hechas por Argentina y Gran Bretaña, que se superponen entre sí.

En el primer caso, la resolución de las controversias fue más expedita, pues en 1947 ambos países formularon la teoría de la existencia de una Antártica Sudamericana a la cual tenían derechos preferentes. Incluso, ante las propuestas formuladas por el gobierno de Estados Unidos en orden a lograr la internacionalización de la Antártica, realizada en 1948, en plena Guerra Fría y con un claro objetivo de excluir a la Unión Soviética del territorio en cuestión, ambas naciones actuaron en conjunto rechazando la idea. Sus argumentos se basaron en la poca efectividad de 
las experiencias anteriores en tal sentido y en que al aceptarse tal proposición se violaría el Tratado de Río de Janeiro pues se permitiría la presencia de potencias extra americanas en el continente blanco.

En el caso de Gran Bretaña la resolución de conflictos fue más compleja. El gobierno de Londres realizó su primera reclamación en 1908 y en ella, por desconocimiento, llegó incluso a incluir territorio chileno continental americano, lo que fue rectificado en 1917.

Treinta años después, ante los acuerdos chileno-argentinos, Gran Bretaña protestó por las actividades realizadas por estos países en la parte de la Antártica que reclamaba para sí, llegando incluso a manifestar su intención de llevar el caso a la Corte Internacional de Justicia. La actitud del gobierno de Santiago fue clara y categórica pues por una parte se reafirmaron los derechos históricos del país, y por otra, se desarrolló la visita antártica del Presidente de la República, Gabriel González Videla, como muestra de una patente defensa de esos derechos. Acto seguido se suscribió una declaración conjunta con el gobierno de Buenos Aires manifestando la intención de actuar en sintonía en la protección de los derechos de ambos en la antártica sudamericana. Esta posición sin duda influyó en el acuerdo que los tres países suscribieron en 1949 para evitar enviar naves de guerra a la zona, exceptuándose los movimientos habituales destinados al aprovisionamiento de las bases existentes y al remplazo de sus dotaciones; sin embargo, esto no se cumplió a cabalidad, como se verá cuando se hable de la etapa de las bases permanentes.

\subsection{EL PERÍODO DE CAZA DE BALLENAS}

Este período comprende los años que van desde 1919 hasta 1942. La actividad ballenera fue relevante, porque permitió el descubrimiento de varias zonas de la geografía antártica. Estos descubrimientos y la utilización de los recursos marinos vivos antárticos abrieron un serio debate sobre el status jurídico que debería tener la Antártida, y plantea las primeras ideas para lo que después se concretaría en el Tratado Antártico. Pero lo más importante de este período es que se fijaron las posiciones jurídicas sobre la Antártida, tanto en el ámbito internacional, como en el ámbito interno de los Estados con intereses territoriales en el continente blanco.

Respecto de las posiciones jurídicas internacionales, una primera postura planteaba la creación de un mecanismo internacional para organizar la cooperación en la Antártida que estaría restringido en general a los países involucrados directamente, es decir, las potencias que tenían pretensiones antárticas y que tenían flotas balleneras, foqueras o científicas en la zona. La segunda postura contemplaba formas de internacionalización basadas en criterios funcionales, que involucraban la cooperación en ámbitos de actividad específicos; y la tercera posición consistía en la internacionalización general de la Antártida, dentro del ámbito de la entonces Sociedad de Naciones, o simplemente la creación de una organización especial para la Antártida (Villamizar, 2012:263). 
Por otra parte, en cuanto al ámbito interno de los Estados con pretensiones territoriales, en este período se realizan la mayoría de las reclamaciones territoriales sobre la Antártida. Aunque no coincide exactamente con las fechas de este período, el hecho de la caza de las ballenas es fundamental para la fundamentación de esta reclamación territorial porque la regulación de la actividad ballenera proveyó el pretexto para algunas de las reclamaciones territoriales ${ }^{4}$ (Dodds, 2009:29).

Los británicos fueron los primeros en presentar un reclamo de la Antártida en 1906, formalizado por medio de Cartas Patentes en julio de 1908. Chile y Argentina también formularon sus respectivas reclamaciones en 1906, aunque la delimitación fue realizada en 1940 y en 1942 respectivamente. Posteriormente, en 1912, Francia hizo su reclamación que delimitó en 1938. Le siguió Nueva Zelanda, que reclamó y delimitó en 1923. Después Noruega reclamó en 1927 la Isla Bouvet, en 1931 la Isla Pedro I y en 1939 una porción del continente. Australia reclamó y delimitó su pretendido territorio en 1933 (Ferrada, 2012:135).

\subsection{LA CAZA DE BALLENAS EN LAS AGUAS CHILENAS}

En 1902, por decreto, el gobierno de Germán Riesco concedió el arriendo de las islas Diego Ramírez y San Idelfonso para fines pesqueros, autorizándose el desarrollo de estas actividades hacia el sur de estos grupos de islas. Cuatro años más tarde, la misma administración autorizó a Enrique Fabry y a Domingo de Toro, para que ocupara y explotara un no despreciable territorio que incluía las islas Diego Ramírez, Shetland y las "Tierras situadas más al sur". También es importante mencionar, dentro del ejercicio jurisdiccional de la autoridad en esa zona, que la Sociedad Ballenera de Magallanes realizó sus labores en época estival, entre 1906 y 1914, contando para ello con la autorización del gobernador de Magallanes y teniendo como base la Isla Decepción.

\subsection{ESTACIONES PERMANENTES}

Este período está comprendido entre los años 1943, cuando se estableció la primera base permanente en Port Lockroy, y 1958, año en el que finalizó el Año Geofísico Internacional.

En 1948, el entonces presidente norteamericano Harry Truman hizo dos propuestas para determinar un régimen legal internacional sobre la Antártida a los siete Estados que habían

4. El aceite de ballena era considerado un bien estratégico. Era empleado con propósitos de iluminación y calefacción, razones por las cuales la regulación de la actividad ballenera era de vital importancia para los Estados interesados, y les sirvió de justificación para exponer sus títulos sobre la parte del territorio antártico que reclamaban. 
realizado reclamaciones territoriales (Villamizar, 2012:263). La primera consistía en poner la Antártida bajo el fideicomiso de la Organización de las Naciones Unidas, de conformidad con los artículos 75,76, 77 y 79 (Capítulo XII) de la Carta de las Naciones Unidas (Department of State, 1948).

El gran inconveniente de esta iniciativa propuesta era netamente jurídico, particularmente en lo referido al alcance legal de lo establecido por el artículo 76, pues según este precepto el fideicomiso debe fomentar la paz y seguridad internacionales, y también la promoción del desarrollo político, económico, social y educativo de la población que habita los territorios sujetos a esta condición. Como es ampliamente sabido, dadas las características propias del inhóspito territorio antártico, en dicho continente no hay población y por lo tanto no podría establecerse un fideicomiso porque no se cumpliría el objetivo para el cual se instaura esta figura (Samuels, 2008:732 y ss.).

La segunda propuesta, que excluía a la otrora Unión Soviética, consistía en una internacionalización limitada de la Antártida por medio de un condominium, en el cual los Estados reclamantes ejercerían una soberanía conjunta de conformidad con las normas de Derecho Internacional Público. Esta propuesta fue largamente discutida y finalmente desechada. En ese contexto fue haciendo carrera el llamado Plan Escudero ${ }^{5}$, que consistía en crear un sistema de modus vivendi, en el que las 7 naciones que reclamaban territorios en el continente blanco suspendieran sus reclamaciones mediante una moratoria y pudieran trabajar conjuntamente en la Antártida, sin que ninguna abandonara sus aspiraciones (Villamizar, 2012:264).

El Plan Escudero no fue acogido inmediatamente y se dilató en el tiempo como opción para solucionar las diversas posiciones sobre la Antártida. Lo que no se dilató en el tiempo fue la pugna entre Chile, Argentina y Gran Bretaña. Estos Estados iniciaron una competencia para sustentar sus respectivas reclamaciones que generó fricciones de consideración, como por ejemplo los disparos realizados en 1952 por marineros argentinos a científicos británicos que intentaban construir una base en Bahía Esperanza (Howkins, 2009:17) y la réplica británica de 1953 con el desmantelamiento de las bases argentinas y chilenas en la Isla Decepción por parte de los tripulantes del barco británico HMS Snipe mediante el bombardeo de dichas bases (Villamizar, 2012:264), pese a que había desde 1949 un acuerdo entre Chile, Argentina y el Reino Unido en el sentido de no enviar buques de guerra al sur de los $60^{\circ}$ de latitud sur, salvo para los movimientos habituales encaminados a atender los relevos de las bases (Pinochet De la Barra, 1981:382).

En ese contexto hostil, se dio inicio a los planes de coordinación para llevar a cabo la tercera versión del año Geofísico Internacional, que tendría lugar entre julio de 1957 y diciembre

5. Llamado así por su creador, el profesor Julio Escudero. 
de 1958. En efecto, durante los primeros años de la década de los cincuenta las grandes potencias mundiales estaban perfilando todo lo necesario para que el Año Geofísico Internacional fuera una realidad. Después de los pasos iniciales que tuvieron lugar entre 1951 y 1953, la Unión Internacional de Geodesia y Geofísica se reunió en Roma en 1954 para crear un Comité Especial, que sesionaría en París entre el 6 y el 10 de julio de 1955. En dicho instancia se acordó un plan para el establecimiento de bases de investigación, se buscó asegurar el principio de libertad científica y se aceptó la necesidad de buscar una solución temporal a las disputas territoriales a fin de garantizar la colaboración científica internacional (Dodds, 2009:40).

En julio de 1957 se inició el Año Geofísico Internacional (1957-1958), que a su vez se enmarcaba en el Tercer Año Polar Internacional, y que se centraba temáticamente en una visión general de los fenómenos naturales del planeta en las zonas ecuatoriales, el Ártico y la Antártida. Dado que la otrora Unión Soviética no facilitó la cooperación internacional en el Ártico, la investigación polar se focalizó en el polo sur (Cabeza, 2011:35). La consecuencia que generalmente se le asigna al Año Geofísico Internacional es el de haber constituido el hito fundamental que posibilitó el Tratado Antártico, aunque hay detractores (Becker, 2010; Dodds, 2006; Scott, 2011).

\subsection{ESTACIONES PERMANENTES CHILENAS}

La reclamación formal de territorios antárticos por parte del gobierno chileno fue materializada a través del decreto 1747, firmado por Pedro Aguirre Cerda el 6 de noviembre de 1940, mediante el cual se estableció que era parte del territorio chileno antártico el espacio comprendido entre $53^{\circ}-90^{\circ}$ longitud oeste ${ }^{6}$. La declaración se aplicó, en 1947, con la construcción de la base naval "Soberanía", que luego se denominó "Arturo Prat", y en 1948 con la instalación de la base del Ejército "General O'Higgins", para posteriormente establecer otras.

\subsection{EL TRATADO ANTÁRTICO}

El Tratado Antártico fue el primer acuerdo firmado por las dos superpotencias después de la iniciación de la Guerra Fría (Krasner, 1989:228), y fue firmado inicialmente por Argentina, Australia, Bélgica, Chile, Francia, Japón, Nueva Zelandia, Noruega, Unión del África del Sur, la otrora Unión de Repúblicas Socialistas Soviéticas, Reino Unido e Irlanda del Norte y Estados Unidos de América. Dentro de las diversas regulaciones del Tratado Antártico, la más relevante para los efectos de este paper es lo concerniente al Artículo IV, pues en virtud de este precepto legal todas las reclamaciones realizadas sobre el territorio antártico quedan suspendidas, no se pueden hacer nuevas reclamaciones y no se pueden ampliar las reclamaciones que ya se han realizado.

6. Especificaba que estaría conformado por las tierras, islas, islotes, arrecifes y glaciares, conocidos y por conocerse, y el correspondiente mar territorial. 


\section{CONCLUSIONES}

En la Introducción de este artículo se plantearon dos preguntas relativas al contexto internacional de las relaciones antárticas y el desarrollo interno de Chile para proceder a reclamar aquello que se conoce como "Territorio Antártico Chileno". En las líneas precedentes se ha podido demostrar cómo la presión internacional fue haciendo que paulatinamente el Estado de Chile actuara de manera reactiva a fin de proteger y consolidar un territorio que ignoraba en los inicios de la República. Es tal la importancia que empieza a tener la Antártida para Chile, que incluso antes de suscribirse el Tratado Antártico, por el cual se congelan las reclamaciones territoriales, se ha mostrado dispuesto a tomar medidas militares para la defensa del territorio en cuestión.

A lo anterior se debe agregar que el Estado chileno debió fijar su atención alternadamente hacia el norte y sur para consolidar sus fronteras internas y externas, siendo una constante la política de resolver los problemas en la medida en que estos fueran apareciendo. La relación con los países vecinos, aunque prioritaria, fue difícil y compleja, pues, como se sabe, conllevó arduas negociaciones y en dos ocasiones, con el Perú y Bolivia en 1838 y 1879, el conflicto se solucionó por medio de las armas. Con Argentina, en 1878 y hacia fines del siglo, estuvo a punto de zanjarse del mismo modo.

Desde la perspectiva antártica, es el gobierno de Manuel Bulnes el que permitió que el Estado chileno pudiera reclamar soberanía en el continente blanco. Con la toma de posesión del Estrecho de Magallanes primero, y con la fundación y consolidación de la ciudad de Punta Arenas después, se estableció la base territorial para proyectar sus intereses hacia el sur. Clave también fue que Chile mantuviera para sí el control de ambas orillas del Estrecho y las islas Nueva, Pícton y Lennox en el canal Beagle. Estas últimas, estarían en el centro de la controversia que en 1978 puso al borde de la guerra, nuevamente, a Chile contra la Argentina.

\section{BIBLIOGRAFÍA}

- $\quad$ Amunátegui, M. (1855). Títulos de la República de Chile a la soberanía y dominio de la estremidad austral del continente americano. Santiago: Imprenta Nacional

- $\quad$ Amundsen, R. (2010). The South Pole. An account of the Norwegian Antarctic Expedition in the "Fram" 1910-1912. Bremen: Europaisher Hochshulverlag GmbH \& Co KG.

- $\quad$ Anrique R. N. (1901). Diario de la goleta Ancud al mando del capitán de fragata don Juan Guillermos (1843) para tomar posesión del Estrecho de Magallanes. Santiago: Imprenta, Litografía y Encuadernación Barcelona.

- $\quad$ Autissier, I. (2006). Kerguelen, le voyageur du pauys de l’ombre. France: Ed. Grasset. 
- Barros Arana, D. (1905). Un decenio de la historia de Chile, 1841 - 1851. 2 Tomos. Santiago: Imprenta y Encuadernación Universitaria.

- $\quad$ Barros Arana, D. (1897). Historia general de Chile. Tomo XIV. Santiago: Rafael Jover Editor.

- Barros Arana, D. (1898). La cuestión de límites entre Chile i la República Argentina. Santiago: Establecimiento Poligráfico Roma.

- Barros Van Buren, M. (1990). Historia diplomática de Chile (1541 - 1938). Santiago: Andrés Bello.

- Becker, F.W.G. (2010). "Some Reflections on the Antarctic Treaty". The Polar Record, Vol 46 Issue n. ${ }^{\circ} 1$, pp. $2-4$.

- Bellingshausen, Fadde- Faddeevich (1945). The Voyage of Captain Bellingshausen to the Antarctic Seas, 1819-1821. London: Hakluyt Society.

- Bocsek, B. A. (1984). The Soviet Union and the Antarctic Regime. American Journal of International Law.

- Braun Menéndez, A. (1974). Pequeña Historia Antártica. Buenos Aires: Editorial Francisco de Aguirre S. A.

- Brunn, G. (1993). La Europa del siglo XIX. 1815 - 1914. Chile: Fondo de Cultura Económica.

- Cabeza, L. (2011). Científicos en el fin del mundo. El conocimiento de los polos como exploración. Madrid: Editorial Hélice.

- $\quad$ Campbell, D. G. (2002). The Crystal Desert. Summers in Antarctica. United States: Mariner Books.

- Cumpston, J. S. and Bicoe, J. (1963). The Antarctic Landfalls of John Biscoe, (Reimpresión de 1831). London: William Clowes Ed.

- $\quad$ D’Urville, J. D. (1834). Voyage de L'Astrolabe. Paris: J. Tastu, Editeur, 1834.

- Debenham, F. (2003). Antarctica: The Story of a Continent. London: Textbook Publishers.

- Dodds, K. (2006). Post-colonial Antarctica: An Emerging Engagement. Polar Record, Vol. 42, Issue n. ${ }^{\circ}$, pp. 59-70. 
- Dodds, K. (2009). La administración del continente polar: los orígenes geopolíticos del Tratado Antártico de 1959. En Istor Revista de Historia Internacional, Año 10, №. 39, 2009, pp. 27-49.

- Edwards, A. (1932). El gobierno de don Manuel Montt. Santiago: Editorial Nascimiento.

- $\quad$ Eyzaguirre, J. (1989). Breve historia de las fronteras de Chile. Santiago: Editorial Universitaria.

- $\quad$ Ferrada Walker, L. V. (2012). Evolución del Sistema del Tratado Antártico: desde su génesis geoestratégica a sus preocupaciones ambientalistas. Revista de Derecho Universidad San Sebastián (Chile), No. 18, 131-151.

- $\quad$ Ferrer Fougá, H. (2003). El hito austral del confín de América. El cabo de Hornos. (Siglos XVI-XVII-XVIII). (Primera parte). Revista de Marina, 6.

- Gogerly, L. (2008). Amundsen and Scott's Race to the South Pole. Pearson Education.

- Harvie, C. (2001). Revolution and the Rule of Law (1789-1851). In: K. O. Morgan (ed.), The Oxford History of Britain (470-517). Great Britain: Oxford University Press.

- Headland, R. K. (1989). Chronological List of Antarctic Expeditions and Related Historical Events. Cambridge: Press Syndicate of the University of Cambridge.

- Headland, R. K. (1992). The Island of South Ceorgia. Cambridge: Press Syndicate of the University of Cambridge.

- Howkins, A. (2009). Más allá del heroísmo: la historia antártica bajo las sombras de Amundsen, Scott y Shackleton. Istor Revista de Historia Internacional, Año 10, №. 39, 2009, pp. 27-49.

- Huntford, R. (2010). Race for the South Pole. The Expedition Diaries of Scott and Amudsen. London: Continuum Books.

- Krasner, S. D. (1989). Conflicto Estructural. El Tercer Mundo contra el liberalismo global. Bueno Aires: Grupo Editor Latinoamericano.

- Martinic, M. (1977). Historia del Estrecho de Magallanes. Santiago: Editorial Andrés Bello.

- Martinic, M. (1988). Punta Arenas en su primer medio siglo. 1848 - 1898. Punta Arenas: Impresos Vanic. 
- Miralles, R. (1996). Equilibrio, Hegemonía y Reparto. Las relaciones internacionales entre 1870 y 1945. Madrid: Editorial Síntesis.

- $\quad$ Pinochet de la Barra, O. (1944). La Antártida Chilena o Territorio Chileno Antártico. Colección de Estudios de Derecho Internacional publicada bajo el patrocinio del Seminario de Derecho Público de la Escuela de Ciencias Jurídicas y Sociales de Santiago (Universidad de Chile). Santiago de Chile.

- Preston, D. (1999). A First Rate Tragedy: Robert Falcon Scott and the Race to the South Pole. United States: Mariner Books.

- Rogers, A. (2012). Evolution and biodiversity of Antarctic Organisms. En Antarctic Ecosystems: An Extreme Environment in a Changing World. United Kingdom: Blackwell Publishing, pp. 417 a 467.

- $\quad$ Ross, M. J. (1994). Polar Pioneers: A Biography of John and James Clark Ross. United Sates: McGill Queen`s University Press.

- Samuels, J. H. (2008). Condominium arrangements in international practice: reviving an abandoned concept of boundary dispute resolution. Michigan Journal of International Law, 29, 732-780.

- Scott, S. V. (2011). Ingenious and innocuous? Article IV of the Antartic Treaty as imperialism. The Polar Journal, Vol.1, Issue 1, 51-62.

- Scott, R. F. (1968). The Diaries of Captain Robert Scott: A Record of the Second Antarctic Expedition 1910-1912. University Microfilms Limited. Ann Harbor.

- Vilanovano, M. (Miguel Servet) (1932). Descripción geográfica del estado actual de las regiones, en la geografía de Claudio Ptolomeo Alejandrino. Madrid: Imprenta y Encuadernación de Julio Cosano.

- Villamizar Lamus, F. (2012). Tratado antártico y mecanismos de protección del territorio antártico. International Law, Revista Colombiana de Derecho Internacional, No. 21, 255295.

- Zegers, C. (1969). Aníbal Pinto. Historia política de su gobierno. Santiago: Editorial Universitaria. 


\section{Documentos}

- Department of State. Memorandum. Draft Communication Regarding the Antarctic. February 19, 1948, Washington D. C.

- Department of State. Memorandum (NOE), February 25, 1948, Washington D. C.

- Cartas de don Domingo Santa María a don José Victorino Lastarria (1918) Revista Chilena, VII (19-20).

- Colección de tratados celebrados por la República de Chile con los estados extranjeros (1857-1875). 2 Vols. Santiago: Imprenta Nacional.

- $\quad$ Constitución de la República de Chile jurada y promulgada el 25 de mayo de 1833 (1833) Santiago: Imprenta de La Opinión.

- $\quad$ Constitución Política del Estado de Chile. Promulgada el 23 de octubre de 1822 (1822). Santiago: Imprenta del Estado.

- $\quad$ Constitución Política de la República de Chile. 1828 (1828). Santiago: Imprenta de R. Rengifo. 